\title{
Anti-HLA hyperimmunization
}

INSERM

\section{Source}

INSERM. (1999). Orphanet: an online rare disease and orphan drug data base. Anti-HLA hyperimmunization. ORPHA:2194

Anti-HLA hyperimmunization is an increase in anti-HLA antigens mostly seen in chronic renal failure (CRF) patients that have undergone hemodialysis and polytransfusion. 